
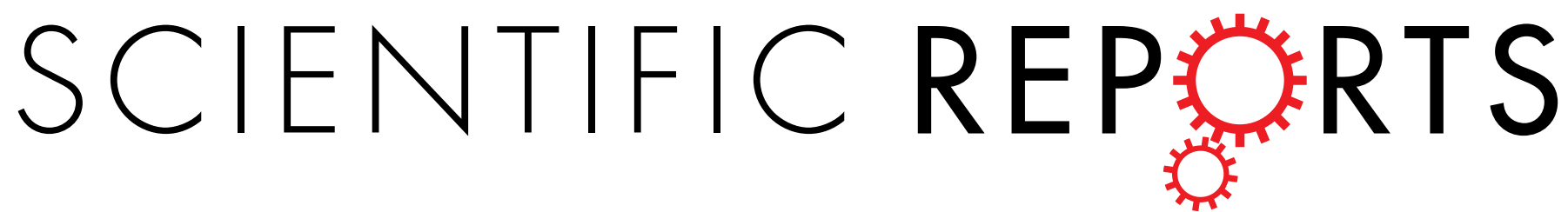

\title{
OPEN Analysing calcium signalling of cells under high shear flows using discontinuous dielectrophoresis
}

Received: 03 March 2015

Accepted: 12 June 2015

Published: 23 July 2015

\author{
Rebecca Soffe ${ }^{1}$, Sara Baratchi ${ }^{2}$, Shi-Yang Tang ${ }^{1}$, Mahyar Nasabi ${ }^{1}$, Peter McIntyre ${ }^{2}$, \\ Arnan Mitchell ${ }^{1} \&$ Khashayar Khoshmanesh ${ }^{1}$
}

Immobilisation of cells is an important feature of many cellular assays, as it enables the physical/ chemical stimulation of cells; whilst, monitoring cellular processes using microscopic techniques. Current approaches for immobilising cells, however, are hampered by time-consuming processes, the need for specific antibodies or coatings, and adverse effects on cell integrity. Here, we present a dielectrophoresis-based approach for the robust immobilisation of cells, and analysis of their responses under high shear flows. This approach is quick and label-free, and more importantly, minimises the adverse effects of electric field on the cell integrity, by activating the field for a short duration of $120 \mathrm{~s}$, just long enough to immobilise the cells, after which cell culture media (such as HEPES) is flushed through the platform. In optimal conditions, at least $90 \%$ of the cells remained stably immobilised, when exposed to a shear stress of $63 \mathrm{dyn} / \mathrm{cm}^{2}$. This approach was used to examine the shear-induced calcium signalling of HEK-293 cells expressing a mechanosensitive ion channel, transient receptor potential vaniloid type 4 (TRPV4), when exposed to the full physiological range of shear stress.

The ability to stably immobilise cells is an important feature in cellular assays, as it enables the physical/ chemical stimulation of cells and monitoring of cellular processes using a variety of microscopic techniques ${ }^{1}$. Classically, the immobilisation of non-adherent cells is acieved by surface modification ${ }^{2}$, which can be accomplished in different ways: such as coating the substrate surface with biomimetic peptides like poly L-lysine or poly ornithine $e^{3,4}$; cell adhesive proteins like laminin or fibronectin ${ }^{5}$; or patterning a suitable ligand onto the substrate which allows cells to attach, spread and migrate along the surface ${ }^{6,7}$.

Important drawbacks of such surface modification approaches are the protein adsorption into the substrate, and the interaction between the cell-substrate may be influenced by different parameters such as surface free energy, charge, roughness, and thickness of modifying layer. Consequently, these surface modifications are often unstable and uneven, and can lead to cellular rearrangement when exposed to a high magnitude of mechanical forces ${ }^{5}$. Furthermore, any surface modification can affect the biology of cells and consequently change cellular responses to the experimental conditions. As such, this approach is not ideal for immobilisation of non-adherent cells, especially when high levels of mechanical stress such as flow-induced shear is required.

Microfluidic systems are widely considered, as enabling technologies in cellular biology research ${ }^{8-10}$. Microfluidic platforms offer reduced sample and reagent volumes, sample diversity, short reaction times, enhanced sensitivity, and the capacity for multiplexing and automation ${ }^{1,8,11}$. Moreover, microfluidic systems enable the quick and controllable immobilisation of cells using a variety of mechanisms, including hydrodynamics ${ }^{12}$, optical tweezing ${ }^{13}$, acoustophoresis ${ }^{14}$, magnetophoresis ${ }^{15}$, and dielectrophoresis ${ }^{16,17}$.

The use of hydrodynamic filters can lead to clogging of the microfluidic channel by trapped cells or debris $^{18,19}$. Moreover, the performance of such filters depends on the size and deformability of the cells, 
such that the filters may need to be redesigned for different cell types ${ }^{12,19}$. In addition, the trapping of cells between structures can potentially limit the amount of shear stress, which can be applied onto the cells ${ }^{18,20}$. Although the use of hydrogels has enabled cells to be immobilised into three dimensional structures, this process is limited to the use of low flow rates, which are not suitable for the investigation of shear-induced stress ${ }^{21,22}$.

Alternatively, "Optical tweezers" rely on sophisticated optical components to produce the desired optical patterns, in particular for producing multi-beam interference patterns for multiple immobilised cells clusters ${ }^{13,23}$. In addition, the exposure of cells to highly focused laser beams can damage them or alter the functionality of cellular proteins ${ }^{24}$. Acoustophoresis enables the label-free and non-invasive manipulation of both single and multiple cells ${ }^{14,25}$. However, the precise control on the vertical location of cells within the microfluidic channel can be challenging, and the cells focused at the same pressure node can be stacked on top of each other. Magnetic tweezers, on the other hand, require the labelling of cells with immuno-magnetic tags ${ }^{15}$.

Dielectrophoresis, the induced motion of polarisable particles such as cells under the influence of non-uniform electric fields, enables the label-free, selective and quick immobilisation of cells in microfluidic systems ${ }^{16,17,26-28}$. Despite these advantages, the long-term exposure of cells to strong electric fields may affect the viability, and functioning of cells ${ }^{17}$. The temperature rise of the medium due to Joule heating effect is another factor that can damage cells ${ }^{29}$. Moreover, the electrical conductivity of the buffer should be reduced to enable the immobilisation of cells, which can damage them in long-term experiments ${ }^{30}$. The immobilised cells can also be exposed to unwanted chemical reactions such as electrolysis, which might happen over the surface of microelectrodes ${ }^{29}$.

Several approaches have been implemented to address these limitations. One such approach is reducing the amount of time that cells are immobilised between the microelectrodes, which is suggested to reduce the negative impacts of strong electric fields, and also temperature rise on cells. In this method, the microelectrodes are switched on/off periodically to enable the quick trap/release of cells. Using this method, Hawkins et al. ${ }^{31}$ limited the immobilisation time of Mycobacterium smegmatis to three seconds, just long enough to measure mycobacterial membrane properties, after which the cells were released. Similarly, Zhang et al. ${ }^{32}$ limited the immobilisation time of yeast cells to $30 \mathrm{~ms}$, just long enough to obtain the Raman signature of the cells, after which cells were released to be sorted based on their Raman spectra. Evidently, this solution does not allow for long-term analysis of cellular responses.

An alternative approach for maintaining cell viability and functioning, involves reducing the amount of time in which immobilised cells are exposed to strong electric fields. For example, in the work presented by Khoshmanesh et al. ${ }^{30}$ the microelectrodes were energised with a voltage of $12 \mathrm{~V}_{\mathrm{pk}-\mathrm{pk}}$ for $10 \mathrm{~min}$ to immobilise the suspended leukemic U937 cells. After which the voltage was reduced to $8 \mathrm{~V}_{\text {pk-pk }}$, just high enough to produce electrothermal vortices within the microfluidic chamber, to enable the constant perfusion of cells with apoptosis inducer drugs over a duration of four hours. Despite some advantages, this system does not allow for long-term experiments, as the cells need to be kept in a low electrical conductivity (LEC) buffer.

Alternatively, Yang et al..$^{33}$ pre-coated the microelectrodes with Anti-Salmonella antibodies. The electric field was applied for a period of 15 to $30 \mathrm{~min}$, to push the Salmonella bacterial cells towards the antibody-coated microelectrodes. This not only enhanced the immune-capture efficiency of cells, but also enabled the stable adhesion of cells once the electric field was switched off. Despite these advantages, the pre-coating of microelectrodes with antibodies complicates the operational process and is specific. Instead, in the work presented by Sebastian et al. ${ }^{34}$ the electric field was only activated for 10 to 15 minutes to create aggregations of Jukart cells over the microelectrodes; after which the electric field was switched off and the LEC buffer was replaced with growth media. The capability of this technique was demonstrated for creating three-dimensional aggregations of cells; however, the aggregated cells were scattered and slightly relocated after a period of one hour under a low shear stress of $0.012 \mathrm{dyn} / \mathrm{cm}^{2}$.

In this paper, we demonstrate a dielectrophoresis-based approach for stable immobilisation of cells and analysis of cellular response under high shear flows. This approach is quick and label-free and does not rely on surface modification. Additionally, it minimises the adverse effects of strong electric fields or low electrical conductivity buffers, on the viability and functioning of cells. This is achieved by activating the field for a short duration of $120 \mathrm{~s}$, just long enough to immobilise the cells, after which cell culture media such as HEPES is flushed through the microfluidic system.

For cell model system, we used HEK-293 cells stably expressing TRPV4 channels, in suspension. TRPV4 is a mechanosensitive calcium permeable ion channels belong to the TRP (transient receptor potential) family of ion channels, which is known to play a key role in controlling vascular homeostasis and tone ${ }^{35-37}$. HEK-293 cells are an excellent cell line to transfect and study TRP channels, as they are easy to work with, and express a very limited range of TRP channels which does not include TRPV4. Such a cell line has been used by us and others to study the characteristics of TRPV $4^{38,39}$. However, one common problem with HEK-293 cells (and many other cell lines) is that they do not adhere well to the glass or plastic substrates, which precludes the study of their response to high magnitudes of shear stress. Hemodynamic forces in the venus and arterial systems are in the range of 10 to $60 \mathrm{dyn} / \mathrm{cm}^{240}$. However, for studying the effect of shear stress on TRPV4-expressing cells, the shear stress is limited to $20 \mathrm{dyn} / \mathrm{cm}^{2}$ or less, largely due to the challenges associated with cells detaching at high magnitudes of shear stress ${ }^{36,38}$. Therefore, the response of the TRPV4 channel to the full physiological range of shear stress has not yet 

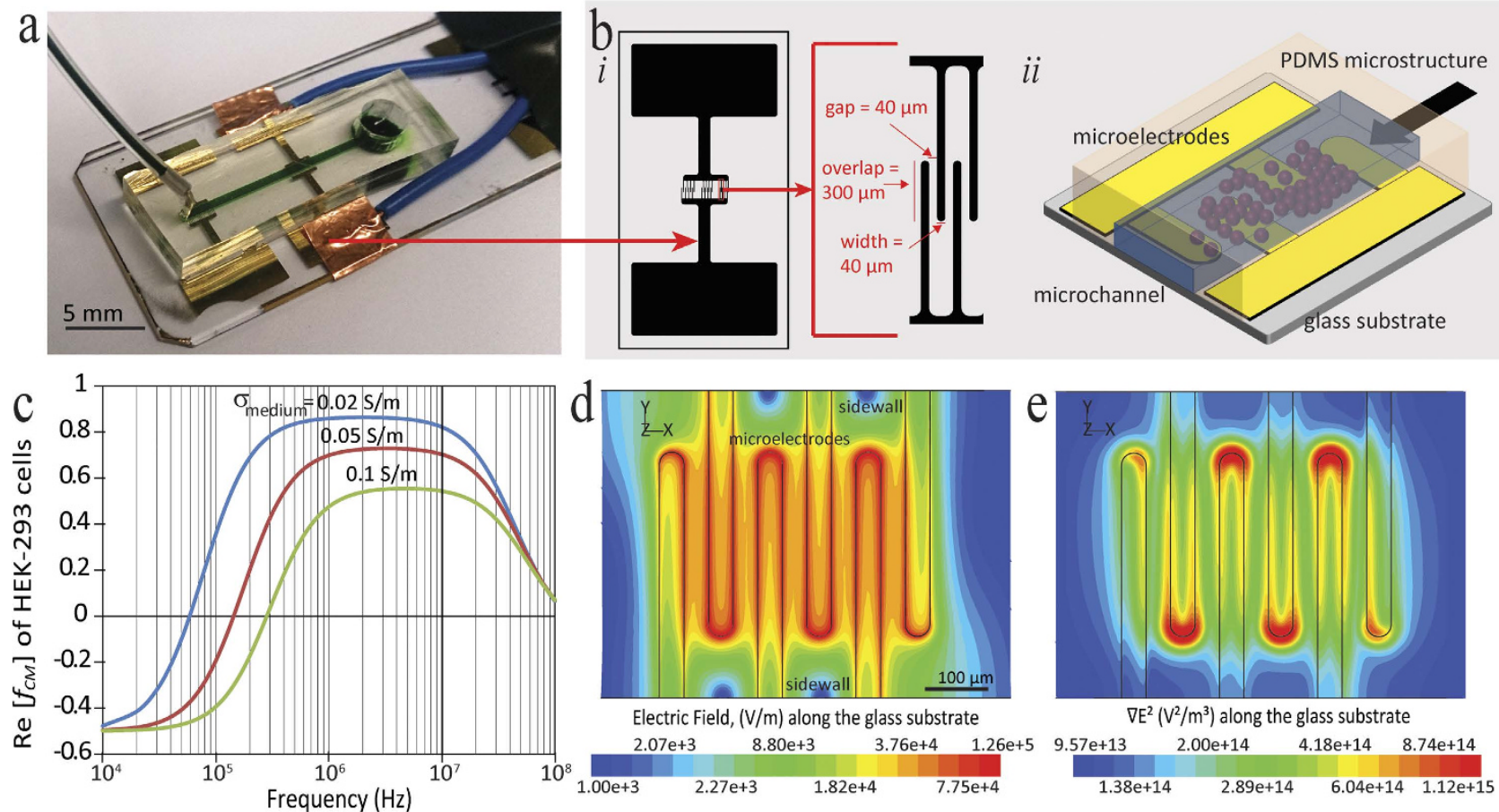

Figure 1. Microfluidic platform used for studying robust immobilisation of cells. (a) The actual microfluidic platform. (b) Plan view of inter-digital microelectrode design with dimensions of microelectrodes. (c) Frequency variation of the real part of the Clausius-Mossotti factor, indicating the DEP response of HEK-293 cells at different frequencies. (d) Contours of electric field at the surface of glass substrate, obtained by numerical simulations at an operating voltage of $5 \mathrm{~V}_{\mathrm{pk}-\mathrm{pk}}$. (e) Contours of the gradient of electric field square at the surface of glass substrate, obtained by numerical simulations at an operating voltage of $5 \mathrm{~V}_{\mathrm{pk}-\mathrm{pk}}$.

been studied. In the present study, up to $90 \%$ of the cells remained stably immobilised, when applying a shear stress of $63 \mathrm{dyn} / \mathrm{cm}^{2}$. This enabled us to examine the shear-induced calcium signalling of HEK293 cells, stably expressing TRPV4 at the full physiological range of shear stress and; additionally, these results were compared to results obtained with non-transfected cells.

\section{Results}

Principles of dielectrophoretic platform. The dielectrophoresis-based microfluidic platform used for the robust immobilisation of cells is displayed as Fig. 1a. This platform utilised inter-digital microelectrodes to create a uniform layer of immobilised cells over the surface of glass substrate. The gap between the microelectrodes and also the width of the microelectrodes were set to $40 \mu \mathrm{m}$ due to the microfabrication limitations; whilst, the overlap length of opposite microelectrodes was set to $300 \mu \mathrm{m}$ (Fig. 1b). A polydimethylsiloxane (PDMS) microfluidic channel with cross-sectional dimensions of $500 \times 80 \mu \mathrm{m}$ $(\mathrm{W} \times \mathrm{H})$, was integrated onto the glass substrate patterned with microelectrodes to facilitate the passage of cells; as schematically shown in Fig. 1b. A reservoir with a diameter of $5 \mathrm{~mm}$ was punched at the inlet of the channel, enabling the cell suspension to be applied to the device, whilst, the flow was withdrawn from the outlet.

The time-averaged DEP force applied on cells can be expressed as below ${ }^{29}$ :

$$
\bar{F}_{D E P}=2 \pi r_{\text {cell }}^{3} \varepsilon_{o} \varepsilon_{\text {medium }} \operatorname{Re}\left[f_{C M}\right] \nabla E_{R M S}^{2},
$$

where, $r_{\text {cell }}$ is the radius of the cell, $\varepsilon_{o}$ is the permittivity of the vacuum which equals to $8.85 \times 10^{-12} \mathrm{~F} / \mathrm{m}$, and $\varepsilon_{\text {medium }}$ is the dielectric constant of the medium. $\operatorname{Re}\left[f_{C M}\right]$ is the real part of the complex Clausius-Mossotti factor, which describes the polarisation of the cell with respect to the surrounding medium. $\operatorname{Re}\left[f_{C M}\right]$ is a function of the cell geometrical and dielectric properties, medium dielectric properties, and the frequency of the applied signal energising the microelectrodes, as detailed in Supplementary Information 1. Finally, $E_{R M S}$ is the root-mean-square value of the electric field induced by microelectrodes.

To demonstrate the capabilities of our approach for the robust immobilisation of cells, we have presented results using a HEK-293 cell suspension. To calculate the Re[ $\left.f_{C M}\right]$ of HEK-293 cells, we determined the first crossover frequency of cells, where transition from negative dielectrophoresis (repelling 
from the microelectrodes) to positive dielectrophoresis (attracting to the microelectrodes) occurs. The crossover frequencies of cells measured at three medium electrical conductivities $\left(\sigma_{\text {medium }}\right)$ of $0.02,0.05$, $0.1 \mathrm{~S} / \mathrm{m}$, were obtained as $55 \pm 7,145 \pm 17$, and $285 \pm 45 \mathrm{kHz}$, respectively. Using the crossover frequency of cells, the $\operatorname{Re}\left[f_{C M}\right]$ of HEK-293 cells was calculated over the frequency range of $10^{4}$ to $10^{8} \mathrm{~Hz}$ (Fig. 1c). In our experiments, the electrical conductivity of the medium was set to $0.02 \mathrm{~S} / \mathrm{m}$. Immobilisation of the HEK-293 cells was achieved by applying a sinusoidal signal of $5 \mathrm{~V}_{\mathrm{pk}-\mathrm{pk}}$, at a frequency of $10 \mathrm{MHz}$, to maximise the magnitude of $\operatorname{Re}\left[f_{C M}\right]$; whilst, minimising the occurrence of electrolysis and electrothermal vortices, which occur at low frequencies.

Figure 1d presents the distribution of electric field generated over the glass substrate, obtained by numerical simulations, as detailed in Supplementary Information 2. Simulations reveal the generation of a strong electric field in the area between the microelectrodes. When applying a sinusoidal signal of $5 \mathrm{~V}_{\mathrm{pk} \text {-pk }}$, electric field strength reaches a maximum of $126 \mathrm{kV} / \mathrm{m}$ along the edges of microelectrodes. The overlapped region of the microelectrodes lies along the middle of the microchannel, and enables the quick trapping of the moving cells. Figure 1e illustrates the contours of $\nabla E_{R M S}^{2}$, generated over the glass substrate, obtained by numerical simulations. According to Equation (1) this term is proportional to the DEP force experienced by the cells. Simulations indicated the generation of a strong DEP force along the edges of microelectrodes, with the maxima at the tip of microelectrodes. This enabled the immobilisation of cells along the entire length of microelectrodes. A stronger DEP force is induced at the tip of the microelectrodes, which potentially leads to the secondary layer of cells accumulating at the tips; however, this secondary layer is washed away upon increasing the flow rate, as described in the following section of the paper. This results in the formation of a single layer of cells immobilised along the width of the microfluidic channel.

Cell immobilisation process. The process used for robust immobilisation of cells is presented in Fig. 2. Initially, the glass substrate patterned with microelectrodes and the PDMS microchannel were cleaned with isopropanol and water, dried with nitrogen, and then assembled using a mechanical clamp to avoid leakage. In the case that the glass substrate and channel are not clean, the cells will not remain immobilised to the substrate in the presence of high flow rates. Water was then flushed through the microchannel, by applying a withdraw flow rate of $2.5 \mu \mathrm{l} / \mathrm{min}$, and then the cells suspended in a LEC (comprising of $8.5 \% \mathrm{w} / \mathrm{v}$ sucrose and $0.3 \%$ dextrose in deionised water) buffer of $0.02 \mathrm{~S} / \mathrm{m}$ were applied to the microchannel (Fig. 2a).

The microelectrodes were then activated using a $5 \mathrm{~V}_{\text {pk-pk }} \mathrm{AC}$ sinusoid at $10 \mathrm{MHz}$, which led to the immobilisation of the cells. The electric field was kept active until the desired population of cells were patterned at the microelectrodes. For example, it takes $120 \mathrm{~s}$ to form the cell pattern presented in Fig. $2 \mathrm{~b}$.

The electric field was then deactivated and the cell suspension within the inlet reservoir was exchanged to HEPES, to ensure the viability and functioning of the cells. It should be noted that HEPES has an electrical conductivity of $1.2 \mathrm{~S} / \mathrm{m}$, such that it cannot be applied to the microchannel in the presence of electric field; if done so it leads to creation of strong electrothermal vortices and bubbles over the surface of microelectrodes. After a minimum incubation time of $10 \mathrm{~min}$ in HEPES buffer, which enabled cells to equilibrate, the flow rate was increased to $5 \mu \mathrm{l} / \mathrm{min}$. The slight increase in flow rate facilitated the removal of loosely joint cells, and also the secondary layers of cells accumulated above the first layer of cells; in turn, leaving a clear view of the cells directly in contact with the substrate, upon observation with an inverted microscope (Fig. 2c). The flow rate was then increased, for example to $120 \mu \mathrm{l} / \mathrm{min}$ to enable the analysis of cells when stimulated with flow-induced shear stress (Fig. 2d).

At the completion of every experiment, the viability of the cells was examined on-chip, through staining the cells with propidium iodide (PI). PI was applied to the cells at a flow rate of $2.5 \mu \mathrm{l} / \mathrm{min}$ for $5 \mathrm{~min}$, to ensure sufficient staining, and the response of cells was observed through the inverted microscope. A similar process was used for the stable immobilisation of Saccharomyces cerevisiae yeast cells.

Cell trapping efficiency. To assess the capability of our approach for the stable immobilisation of cells, we measured the trapping efficiency of the HEK-293 cells when exposed to flow-induced shear stress. These cells are loosely adherent cells, and can be easily dislodged by fluid flow. For comparison, the adhesion force of HEK-293 cell is one order of magnitude less than that of HeLa cell, which is an adherent cell line ${ }^{41}$. The common approach to improve the adhesion of these cells is to pre-coat the glass surface with poly-L-lysin or collagen ${ }^{42}$. Other methods such as surface modification of glass substrates with positively charged polymers such as poly-ethyleneimine ${ }^{42}$, and modifying cell's integrin expression profile $^{43}$, have been also demonstrated to enhance the adhesion properties of these cells.

In doing so, following the immobilisation of cells at a flow rate of $2.5 \mu \mathrm{l} / \mathrm{min}$, the flow rate was sequentially increased every $3 \mathrm{~min}$ to $5,10,20,40,60$, and $100 \mu \mathrm{l} / \mathrm{min}$. The trapping efficiency was calculated as $\zeta_{\text {trapping }}=n_{\text {remained }} / n_{\text {initial }} \times 100 \%$, in which $n$ is the number of cells; with the initial value corresponding to the number of cells present at $5 \mu \mathrm{l} / \mathrm{min}$, as presented in Fig. 3. Experiments were repeated three to five times.

Assuming that the patterned cells do not modify the hydrodynamics of the microfluidic channel, applying flow rates of $5,10,20,40,60$, and $100 \mu \mathrm{l} / \mathrm{min}$ led to inducing of shear stress values of $1.75,3.5$, $7,14,21$ and $35 \mathrm{dyn} / \mathrm{cm}^{2}$, respectively, over the surface of the cells. Shear stress values were obtained 


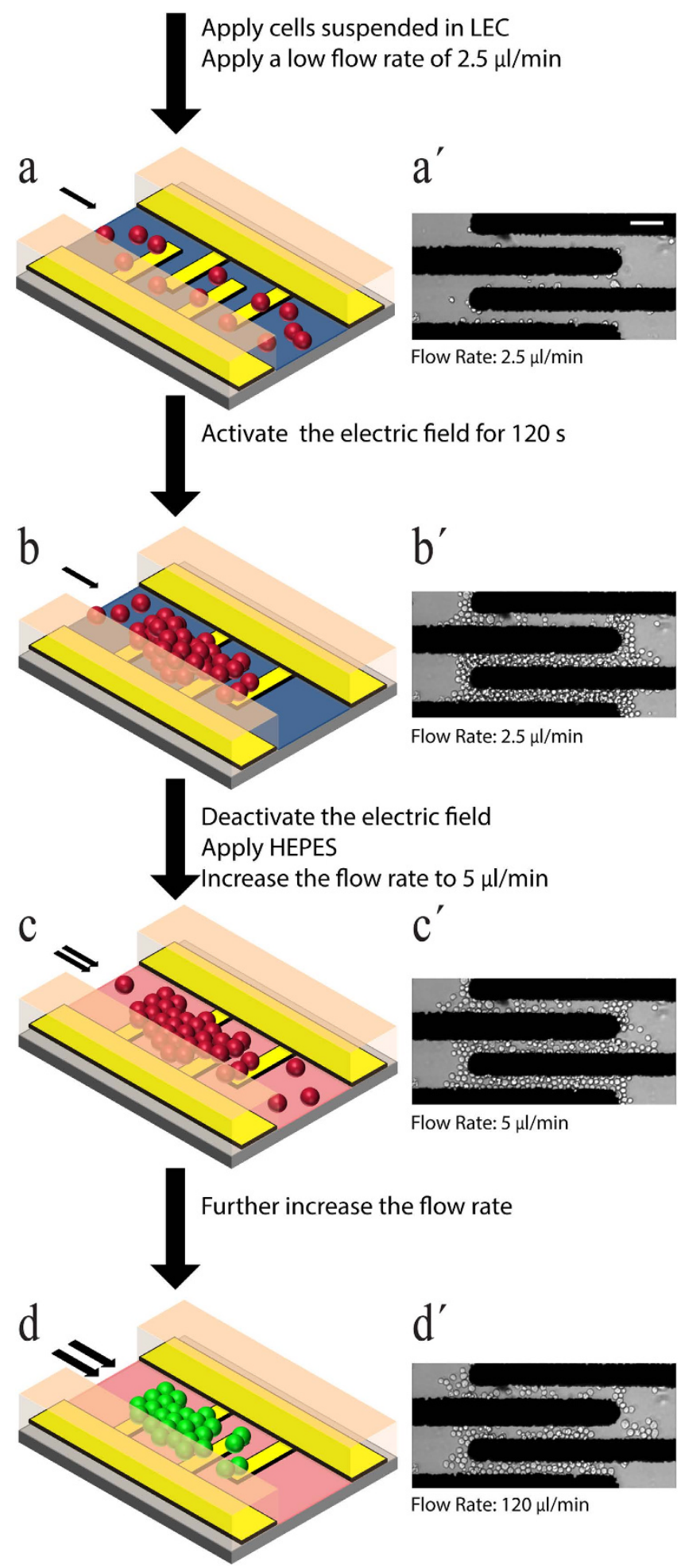

Figure 2. Robust Cell Immobilisation Process. (a-d) Schematic representation of the immobilisation process with $\left(\mathbf{a}^{\prime}-\mathbf{d}^{\prime}\right)$ corresponding experimental results presented for the case when a high flow rate of $120 \mu \mathrm{l} / \mathrm{min}$ is applied to the immobilised cells. (a) Cells suspended in LEC are applied to the microfluidic platform at a low flow rate of $2.5 \mu \mathrm{l} / \mathrm{min}$. (b) Electric field is activated for $120 \mathrm{~s}$ to immobilise the cells between the microelectrodes. (c) Electric field is deactivated, after which HEPES buffer is flushed through the microfluidic platform. After $10 \mathrm{~min}$, the flow rate is increased to $5 \mu \mathrm{l} / \mathrm{min}$ to remove the loosely joint cells, and especially the secondary layers of cells. (d) The flow rate is then increased to desired values. Scale Bar: $50 \mu \mathrm{m}$. 

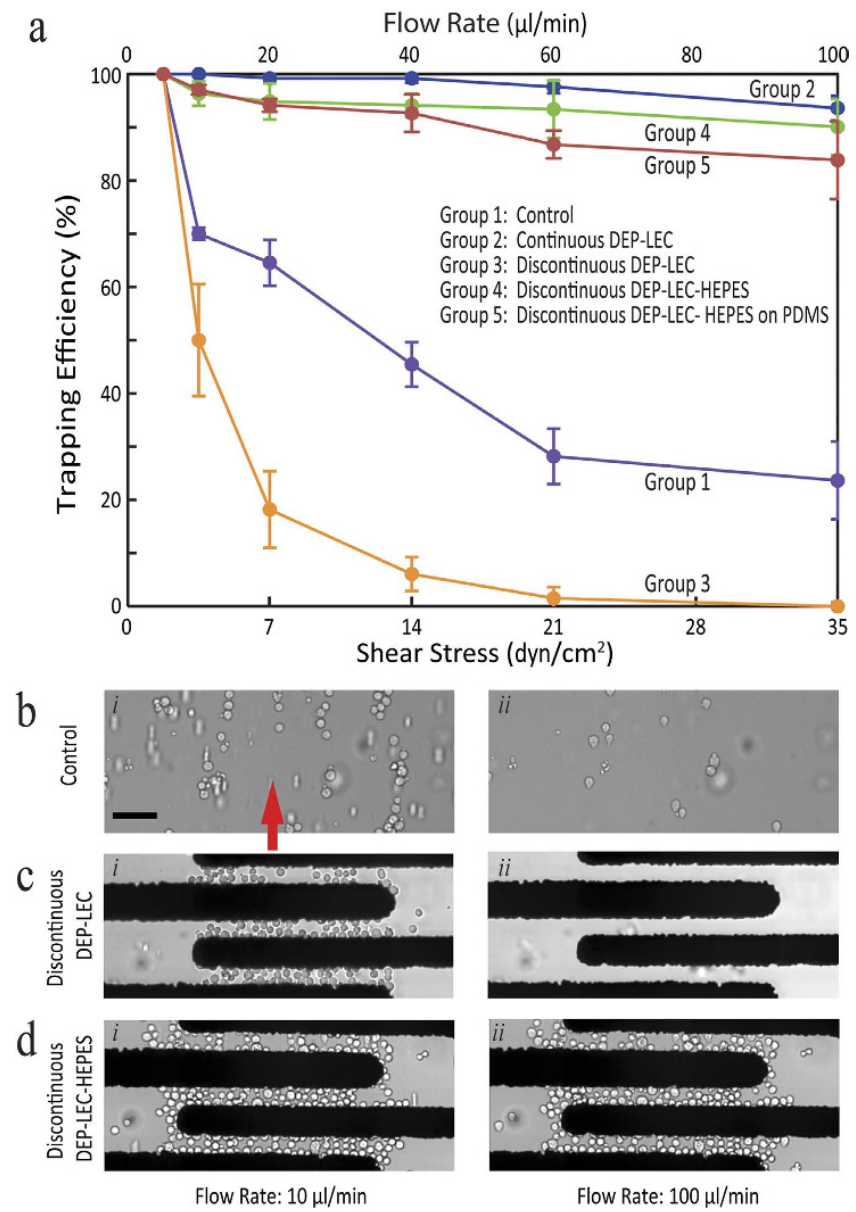

Figure 3. Cell Trapping Efficiency. (a) The trapping efficiency obtained for experimental groups one to five. (b-d) Images compare the cell population for experimental groups one, three and four, obtained at the flow rates of 10 and $100 \mu \mathrm{l} / \mathrm{min}$. Group-one: no electric field is used to immobilise cells with cells suspended in HEPES, group-three: discontinuous DEP after $120 \mathrm{~s}$ with cells suspended in LEC, and group-four: discontinuous DEP after $120 \mathrm{~s}$, after which the medium is changed to HEPES. The flow direction is indicated by the red arrow and applies to all presented experimental images. Data is representative of three to five independent experiments and error bars indicate mean \pm SEM. Scale Bar: $50 \mu \mathrm{m}$.

through numerical simulations, as detailed in Supplementary Information 3. For the microfluidic channel used in our experiments, the correlation between the flow rate and the shear stress can be expressed as $\tau=67.2 \mu \mathrm{Q} / W H^{2}$; where, $\mu$ is buffer's viscosity, $Q$ is flow rate, and $W$ and $H$ are the width and height of the microfluidic channel, respectively.

To determine the sensitivity of our cell immobilisation process to different operating conditions, we performed five groups of experiments; as explained below with the results presented in Fig. 3a:

- Group-one (control): no electric field was applied, and the cells suspended in HEPES were allowed to rest over the substrate within $30 \mathrm{~min}$ in the absence of flow (Fig. 3b);

- Group-two (continuous DEP-LEC): the electric field was applied through the entire duration of the experiment, and the cells were kept in LEC;

- Group-three (discontinuous DEP-LEC): the electric field was applied for only $120 \mathrm{~s}$, and the cells were kept in LEC (Fig. 3c);

- Group-four (discontinuous DEP-LEC-HEPES): representing our immobilisation approach where the electric field was applied for only 120 s, after which the LEC suspension was exchanged for HEPES (Fig. 3d);

- Group-five (discontinuous DEP-LEC-HEPES on PDMS): similar to group-four, however the glass substrate was exchanged for a PDMS substrate.

It should be noted that in groups two to five, the electric field was generated by energising the microelectrodes with a $5 \mathrm{~V}_{\mathrm{pk}-\mathrm{pk}} \mathrm{AC}$ sinusoid at $10 \mathrm{MHz}$. Group-one led to a trapping efficiency of $24 \%$. The process of patterning cells was time-consuming and also did not offer any control over the location of patterned 
cells. In comparison, group-two led to a trapping efficiency of $93 \%$ at a flow rate of $100 \mu \mathrm{l} / \mathrm{min}$, which was significantly higher than that of group-one (see Supplementary Movie 1). Despite such a high trapping efficiency, the continuous exposure of cells to electric field could potentially damage the cells $s^{17,30}$. In turn, this led us to discontinue the electric field after $120 \mathrm{~s}$, which was long enough for a sufficient cell population to be immobilised (group-three). However, in this case, the trapping efficiency sharply reduced to $48 \%$ at a flow rate of $10 \mu \mathrm{l} / \mathrm{min}$, and further dropped to zero at a flow rate of $100 \mu \mathrm{l} / \mathrm{min}$ (see Supplementary Movie 2). Such a weak trapping efficiency led us to exchange HEPES for LEC, after discontinuing the electric field (group-four). This led to a trapping efficiency of $91 \%$, which was significantly higher than that of group-three, and was very similar to the results obtained from group-two (see Supplementary Movie 3). Our extended experiments indicated that for group-four experiments, the trapping efficiency is greater than $90 \%$, even at a shear level of $63 \mathrm{dyn} / \mathrm{cm}^{2}(180 \mu \mathrm{l} / \mathrm{min})$. However, at this shear stress level, some cells were seen to drift slightly, without detaching from the substrate.

The increased trapping efficiency obtained from group four, clearly highlights the role of cell extracellular environment in modulating the adhesion of cells to the glass substrate. This can be attributed to better adhesion properties of cell adhesion molecules (CAMs) in HEPES compared to LEC, enabling cells to withstand high shear stresses. CAMs are transmembrane proteins, which facilitate the adhesion of cells to a surface ${ }^{44}$. Among different CAMs, integrins are the major class of proteins involved in cell adhesion $^{44,45}$. Several studies have revealed that the adhesion properties of integrins are strongly dependent on the presence and interplay of $\mathrm{Ca}^{2+}$ and $\mathrm{Mg}^{2+}$ cations in the buffer ${ }^{46,47}$. The absence of these two cations in LEC buffer can be the potential reason behind the decreased adhesion of HEK-293 cells to glass, in comparison to when the cells are suspended in HEPES.

To investigate if our immobilisation process depends on the material of the substrate, we replaced the glass substrate with a PDMS-coated substrate, with patterned gold/chrome microelectrodes on its surface $^{48}$; where, we repeated the case of discontinuous DEP-LEC-HEPES on a PDMS substrate (group-five). This led to a trapping efficiency of $83 \%$ at a flow rate of $100 \mu \mathrm{l} / \mathrm{min}$, which was slightly lower than that of group-four.

Furthermore, to investigate the effect of the applied voltage on the trapping efficiency of cells, we repeated the experiments associated with group-two, three, and four at different signal voltages of 2.5, 5 , and $10 \mathrm{~V}_{\mathrm{pk}-\mathrm{pk}}$ (Supplementary Information 4). The results indicated that for the case of continuous DEP-LEC (group-two), increasing the voltage to $10 \mathrm{~V}_{\mathrm{pk} \text {-pk }}$ reduces the trapping efficiency of cells. However, for the case of discontinuous DEP-LEC (group-three) changing the applied voltage did not improve the trapping efficiency. Alternatively, for the case of discontinuous DEP-LEC-HEPES (group-four), increasing the voltage to $10_{\mathrm{pk}-\mathrm{pk}}$ slightly improved the trapping efficiency at low flow rates of $<20 \mu \mathrm{l} / \mathrm{min}$ but led to less trapping efficiencies at higher flow rates. These results suggest that an applied voltage of $5 \mathrm{~V}_{\mathrm{pk} \text {-pk }}$ is optimal for the robust immobilisation of cells for group-four. Our experiments indicated that increasing the voltage escalates the density of cells immobilised between the first microelectrode pair, and leads to formation of multiple cells stacked on top of each other, which can be easily detached at high flow rates. Alternatively, at lower voltages (close to the optimal voltage of $5 \mathrm{~V}_{\mathrm{pk} \text {-pk }}$ ) the cells were immobilised between the consequent microelectrode pairs more uniformly, and could withstand high flow rates. Moreover, applying high voltages might lead to conformational changes within the CAMs such as integrin, compromising their adhesion properties ${ }^{49}$.

In addition, in order to investigate the effect of the applied frequency on the trapping efficiency of cells, we repeated the group-four experiments at different frequencies ranging from 1 to $15 \mathrm{MHz}$. The results indicate that changing the frequency in the range of 5 to $12 \mathrm{MHz}$ leads to similar trapping efficiencies obtained at $10 \mathrm{MHz}$.

Furthermore, we conducted a series of experiments to examine the proficiency of our approach for the robust immobilisation of Saccharomyces cerevisiae yeast cells. These cells have a poor adhesion to glass surfaces. Yeast cells are generally ellipsoidal (non-spherical) shaped, which further weakens their adhesion due to electrostatic and hydrophilic repulsive forces. Yeast cells that are more spherical in nature are more adhesive; additionally, their adhesion properties can be further improved by increasing the ionic strength of the buffer ${ }^{50}$.

The yeast cells were immobilised following the procedure shown in Fig. 2, and the trapping efficiency was measured across the flow rates of 10 to $100 \mu \mathrm{l} / \mathrm{min}$ (Supplementary Information 5). For the case of discontinuous DEP-LEC (group-three) a low trapping efficiency of $27 \%$ was obtained at a flow rate of $100 \mu \mathrm{l} / \mathrm{min}$. In comparison, for the case of discontinuous DEP-LEC-HEPES, the trapping efficiency increased to $82 \%$ at the same flow rate (see Supplementary Movie 4). The increased trapping efficiency of yeasts in HEPES at high flow rates is in line with the results obtained for HEK-293 cells presented in Fig. 3a; and again highlights the role of cell extracellular environment in modulating the cell adhesion to the substrate. More importantly, it shows that our immobilisation approach is not limited to HEK-293 cells, and can potentially be applied to other non-adherent cells.

Cell viability. To examine whether our immobilisation approach affects the viability of the cells, we compared the viability of the patterned cells over a $240 \mathrm{~min}$ duration, using propidium iodide (PI) staining and fluorescence microscopy. Following the immobilisation of cells at a flow rate of $2.5 \mu \mathrm{l} / \mathrm{min}, \mathrm{PI}$ 


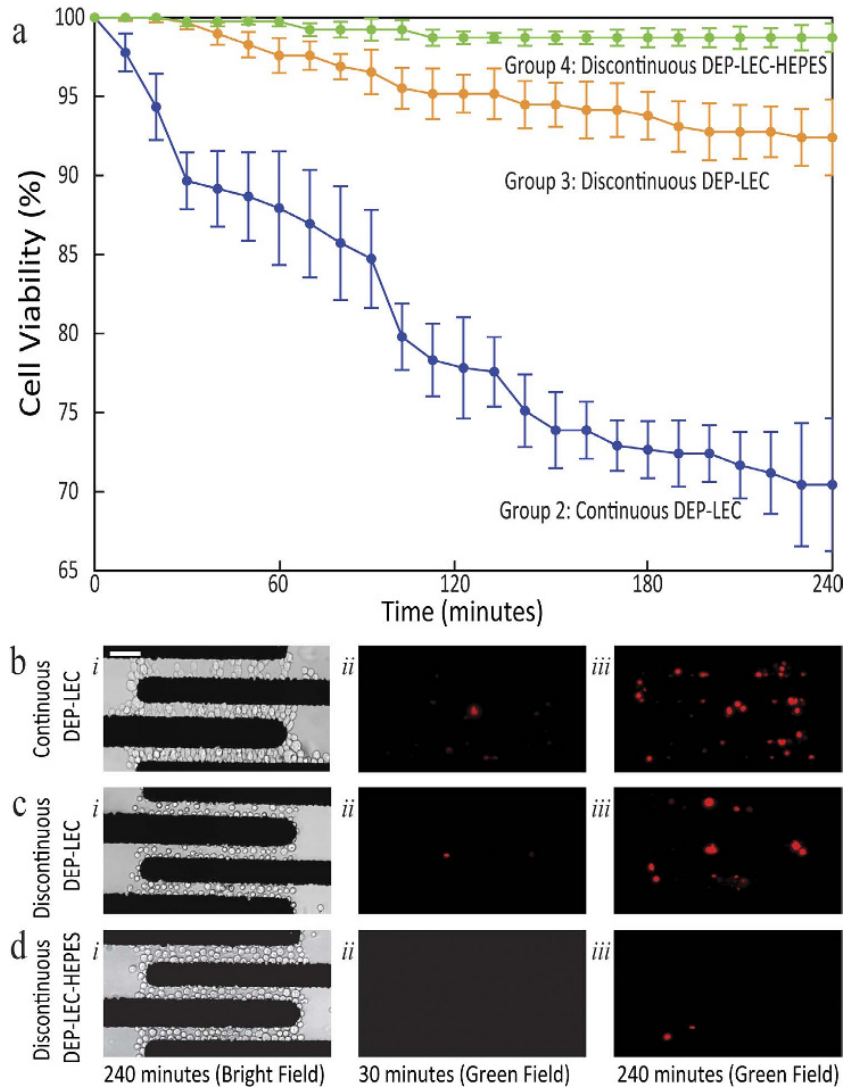

Figure 4. Viability of the Cells. (a) The viability of immobilised cells is displayed for three different groups, including group-two: continuous DEP-LEC, group-three: discontinuous DEP-LEC, and groupfour: discontinuous DEP-LEC-HEPES. In all cases, fresh suspension medium either, LEC or HEPES was supplied continuously over $240 \mathrm{~min}$, at a low flow rate of $2.5 \mu \mathrm{l} / \mathrm{min}$. (b-d) Experimental results for each experimental group. (i) Bright field image, after $240 \mathrm{~min}$, presenting the entire population of both viable and non-viable cells. (ii) Fluorescence images, highlighting the non-viable cells after $30 \mathrm{~min}$. (iii) Fluorescence images, highlighting the non-viable cells after $240 \mathrm{~min}$. Data is representative of three to three independent experiments and error bars indicate mean \pm SEM. Scale Bar: $50 \mu \mathrm{m}$.

was flushed through the microchannel, and the viability was calculated as $\zeta_{\text {viability }}=\left(n_{\text {total }}-n_{P I}\right.$ positive $) /$ $n_{\text {total }} \times 100 \%$, where $n$ is the number of cells.

To identify the sensitivity of cells to operating conditions of the system, we performed three groups of experiments corresponding to group-two (continuous DEP-LEC), three (discontinuous DEP-LEC), and four (discontinuous DEP-LEC-HEPES), explained in the previous section, with the results presented in Fig. 4a.

Group-two (continuous DEP-LEC), which is commonly used in dielectrophoresis based experiments, led to a viability rate of $72 \%$ after $240 \mathrm{~min}$ (Fig. 4b). In comparison, group-three (discontinuous DEP-LEC) led to a viability rate of $92 \%$ after $240 \mathrm{~min}$ (Fig. 4c), which is significantly higher than that of group-two, and clearly indicates the adverse effect of continuous electric field on the viability of cells, which can be associated with the effects such as Joule heating of the surrounding medium, trans-membrane potential interaction and reorganisation/activation of cell membrane components ${ }^{17,29}$. Finally, group-four (discontinuous DEP-LEC-HEPES) led to a viability rate of $98 \%$ after $240 \mathrm{~min}$ (Fig. 4d), which is slightly higher than that of group-three, and highlights the adverse effect of LEC buffers on the viability of cells, which can be associated with the lack of various essential salts, the inability for maintaining physiological $\mathrm{pH}$ of the media, and insufficient conductivity similar to biological environments ${ }^{16,51}$.

Shear-induced calcium signalling of TRPV4-HEK-293 cells. Due to the ability of the immobilised cells to withstand high flow rates, we were able to investigate the shear-induced calcium signalling of HEK-293 cells, stably expressing TRPV4 in a microfluidic channel; and compare them with the response of non-transfect HEK-293 cells.

Cells were loaded for $30 \mathrm{~min}$ with Fluo-4AM dye as previously described ${ }^{38}$, and then carefully diluted in LEC, such that $20 \mu \mathrm{l}$ of the loaded cells were suspended into $1000 \mu \mathrm{l}$ of LEC; ensuring to 


\section{TRPV4-HEK293 Shear Stress: $10.5 \mathrm{dyn} / \mathrm{cm}^{2}$}

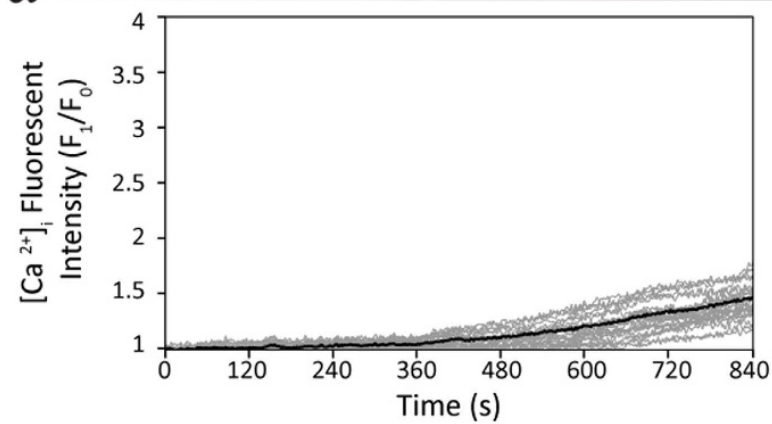

C TRPV4- HEK293 Shear Stress: $63 \mathrm{dyn} / \mathrm{cm}^{2}$
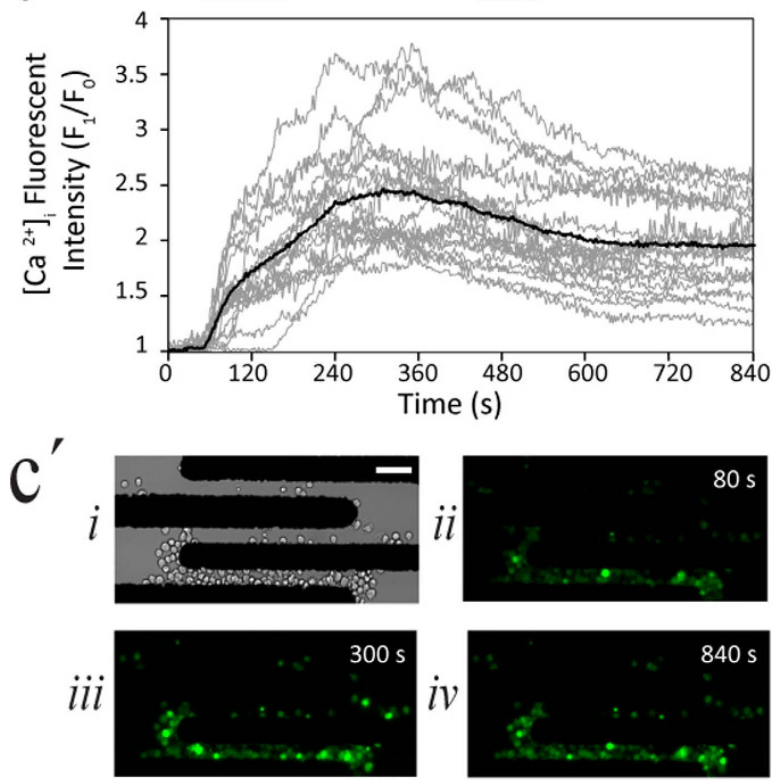

b TRPV4-HEK293 Shear Stress: $42 \mathrm{dyn} / \mathrm{cm}^{2}$

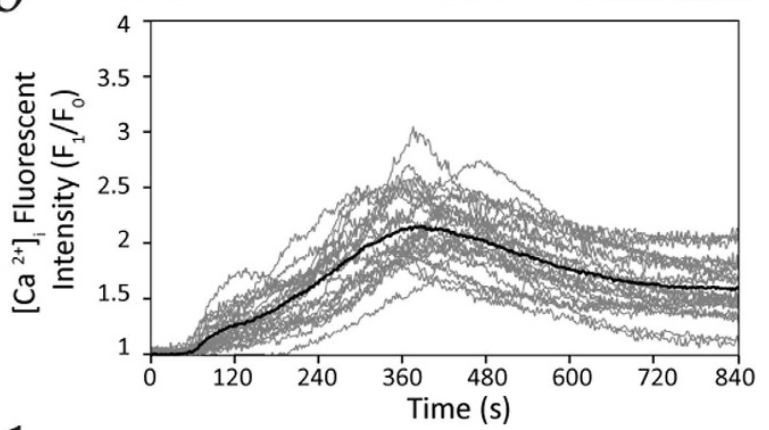

Non-transfected-HEK293 Shear Stress: 63 dyn/cm

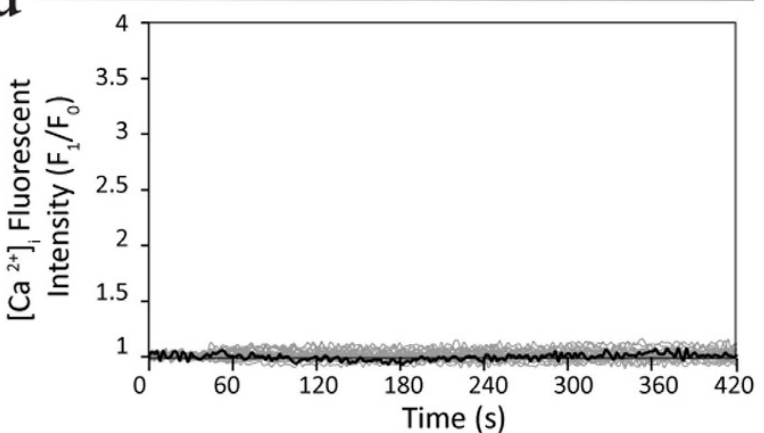

Flow rate ( $\mu$ lit/min)
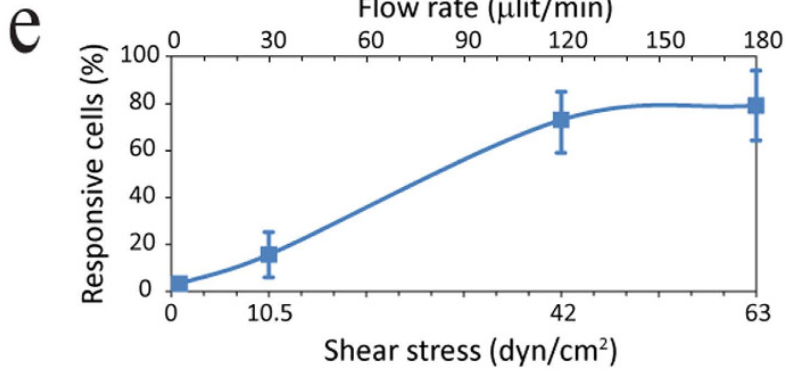

Figure 5. Application of the dielectrophoresis-based immobilisation process for analysis of shearinduced calcium signalling. (a-d) Each graph represents the normalised single cell intensity profiles of 30-50 cells obtained over a duration of $840 \mathrm{~s}$ under different shear stresses. Note that increasing the shear stress elevates the average fluorescent intensity from (a) 1.54 at $10 \mathrm{dyn} / \mathrm{cm}^{2}$ to (b) 2.27 and to (c) 2.49 at 42 and $63 \mathrm{dyn} / \mathrm{cm}^{2}$, respectively. (c') shows representative (i) bright field and (ii-iv) fluorescent images of immobilised TRPV4-HEK-293 cells loaded with Fluo-4AM acquired at 80, 300, and 840 s upon application of $63 \mathrm{dyn} / \mathrm{cm}^{2}$ shear stress. (d) non-transfected HEK-293 cells did not show any response to shear stress even at $63 \mathrm{dyn} / \mathrm{cm}^{2}$. (e) Bar graph shows that increasing the shear stress elevates the percentage of activated cells. Data is representative of three independent experiments and error bars indicate mean \pm SEM. Note that an increase in Fluo-4AM fluorescent intensity indicates increase in $\left[\mathrm{Ca}^{2+}\right]_{\mathrm{i}}$. Scale Bar: $50 \mu \mathrm{m}$.

avoid pre-exposure of cells to shear stress. Once the cells were immobilised by means of dielectrophoresis (explained in Fig. 1), the flow rate was increased to achieve the desired level of shear stress. Simultaneously, the intracellular calcium level, $\left[\mathrm{Ca}^{2+}\right]_{\mathrm{i}}$ was quantified by measuring the changes in the intensity of the Fluo-4AM compared to the basal level, as presented in Fig. 5.

The Fluo-4AM fluorescent intensity measurements obtained over a duration of $840 \mathrm{~s}$ were normalised to the resting cell intensity, to obtain an intensity profile for individual cells at different flow rates of $30 \mu \mathrm{l} /$ min (Fig. 5a), $120 \mu \mathrm{l} / \mathrm{min}$ (Fig. 5b), and $180 \mu \mathrm{l} / \mathrm{min}$ (Fig. 5c). Three time-lapse images taken at 80, 300, and $840 \mathrm{~s}$ are presented in Fig. $5 \mathrm{c}^{\prime}$, respectively for a flow rate of $180 \mu \mathrm{l} / \mathrm{min}$. Time-lapse images for flow rates of 30, and $20 \mu \mathrm{l} / \mathrm{min}$ are given in Supplementary Information 6 .

Our experiments indicated that higher levels of shear stress reduce the time taken for cellular calcium levels to start increasing. For example, at shear stress values of $42 \mathrm{dyn} / \mathrm{cm}^{2}(120 \mu \mathrm{l} / \mathrm{min})$ and $63 \mathrm{dyn} / \mathrm{cm}^{2}$ (180 $\mu \mathrm{l} / \mathrm{min})$, TRPV4-HEK-293 cells responded to shear within $77 \pm 6$ and $53 \pm 21 \mathrm{~s}$, respectively; whilst, at a shear stress of $10.5 \mathrm{dyn} / \mathrm{cm}^{2}(30 \mu \mathrm{l} / \mathrm{min})$, the cellular calcium was still increasing slowly at $360 \pm 28 \mathrm{~s}$, 
and did not reach a plateau during the duration of the experiment. In addition, experiments indicated that higher levels of shear stress reduce the time taken for cellular calcium levels to reach their maximum value. For example, increasing the shear to $42 \mathrm{dyn} / \mathrm{cm}^{2}(120 \mu \mathrm{l} / \mathrm{min})$ and $63 \mathrm{dyn} / \mathrm{cm}^{2}(180 \mu \mathrm{l} / \mathrm{min})$, reduced the peak response time to $392 \pm 18$ and $253 \pm 32$ s, respectively (Fig. 5a-c).

Furthermore, we found that increasing the shear stress increases the magnitude of the maximal intracellular calcium level from $1.46 \pm 0.03$ at $10.5 \mathrm{dyn} / \mathrm{cm}^{2}(30 \mu \mathrm{l} / \mathrm{min})$, to $2.27 \pm 0.07$ and $2.49 \pm 0.1$ at $42 \mathrm{dyn} / \mathrm{cm}^{2}(120 \mu \mathrm{l} / \mathrm{min})$, and $63 \mathrm{dyn} / \mathrm{cm}^{2}(180 \mu \mathrm{l} / \mathrm{min})$, respectively (Fig. $\left.5 \mathrm{a}-\mathrm{c}\right)$. It should be noted that the control negative group (non-transfected HEK-293 cells) did not show any response to shear stress (Fig. 5d). Additionally, our experiments indicated that increasing the shear stress elevates the percentage of activated cells from $3.25 \pm 1.2 \%$ at a shear level of $1.75 \mathrm{dyn} / \mathrm{cm}^{2}$ to $15.67 \pm 8.9,73.1 \pm 12.5$, and $79.3 \pm 14.3$, at shear levels of $10.5,42$ and $63 \mathrm{dyn} / \mathrm{cm}^{2}$, respectively (Fig. $5 \mathrm{e}$ ).

At the completion of the experiment, the viability of the cells was examined by applying PI suspended in HEPES, at a flow rate of $2.5 \mu \mathrm{l} / \mathrm{min}$. The calcium signalling of the non-viable cells was excluded from the analysis.

\section{Discussion}

Here, we have demonstrated the robust immobilisation of cells using discontinuous dielectrophoresis. In contrast to conventional immobilisation methods, our approach does not rely on substrate modification. The method enables dynamic control of the microenvironment, and parallelisation. More importantly, it provides the ability to apply a very high magnitude of shear over the immobilised cells, which was not previously possible.

The proposed approach will open new horizons to study the mechanotransduction of non-adherent cells. Mechanotransduction is a process by which cells are able to sense the mechanical stress that they receive from the surrounding environment, and translate it into biochemical signals. Cellular response to mechanical stress modulates a diverse range of cellular functions such as proliferation, differentiation, migration, and is crucial for cellular homeostasis and function ${ }^{52}$.

Due to limitation of available tools, the identity and mechanism of action of mammalian mechanoreceptors remains poorly understood. It is not clear how cells transduce the mechanical signals that they receive from the surrounding environment; and there is much debate about the nature of the primary mechanosensing molecules. Mechanical stimulation across the full physiological range remains difficult for non-adherent or loosely adherent cells, since they might be washed away using conventional approaches.

The proposed method allows us to stably immobilise cells in suspension, and apply shear stress from the low end of the physiological range to the high end; whilst, measuring fluorescent readouts of individual cellular responses using microscopy. Immobilisation was achieved by activating the electric field for a short duration of $120 \mathrm{~s}$, after which the electric field was deactivated and HEPES was flushed through the microchannel. This approach overcomes two major limitations of dielectrophoresis, including the long-term exposure to strong electric fields, and the use of low electrical conductivity isotonic buffers, which both can affect the viability and functionality of cells. It should be noted that the use of dielectrophoresis to immobilise different mammalian cells while maintaining their viability and functionality has been demonstrated in several studies ${ }^{30,34,53-55}$. The magnitude of electric field, and the time that immobilised cells are exposed to electric field, are the two major factors that can contribute to the loss of viability and functionality of cells. To highlight the features of our approach, we have compared these two factors in our study to conditions used in the literature, as given in Table 1. The maximum electric field applied to the cells in our study is $126 \mathrm{kV} / \mathrm{m}$ (Fig. $2 \mathrm{~d}$ ), which is comparable to values in the literature; however, the time that cells are exposed is limited to $120 \mathrm{~s}$ in our study, which is considerably less than those in the literature, which is less likely to damage fragile mammalian cells.

We are interested in mechanosensitive ion channels and changes of $\left[\mathrm{Ca}^{2+}\right]_{\mathrm{i}}$ and the majority of available literature on shear stress studies is limited to low shear flows. The ability to examine high shear flows is important, as there is a potential for other mechanosensitive ion channels that are yet to be identified due to possessing a high shear threshold.

Using this method, the shear stress response of TRPV4 channels was investigated. TRPV4 is a $\mathrm{Ca}^{2+}$ permeable ion channel, wildly expressed in different organs; additionally, its response to mechanical stress is linked to different physiological and pathological conditions ${ }^{36,38,56}$. For example, in vascular endothelium TRPV4 controls the vasodilation of smooth muscle cells in response shear stress ${ }^{56}$. As such, understanding the signalling pathways regulating mechanosensitivity of TRPV4 is highly valuable for clinical pharmacology. So far available literature has not been able to report a clear shear stress response from cells expressing TRPV4; which will influence understanding of underlying subcellular responses, mainly due to limitation of available methods. Using our approach, we were able to apply high levels of shear stress, and obtained clear increase in $\left[\mathrm{Ca}^{2+}\right]_{\mathrm{i}}$ that was dose dependent, and also influenced the percentage of cells responding to shear stress.

Although we used our approach for studying the shear-induced calcium signalling of cells, it has the potential to be applied to a wide range of cellular assays, in particular, where the non-adherent cells are required to be immobilised, then stimulated either chemically or physically, and monitored in real-time. 


\begin{tabular}{|c|c|c|c|c|}
\hline Cell type & Purpose & $\begin{array}{l}\text { Magnitude of } \\
\text { electric field }\end{array}$ & $\begin{array}{l}\text { Duration of } \\
\text { exposure to } \\
\text { electric field }\end{array}$ & Ref. \\
\hline U937 Leukemia & $\begin{array}{l}\text { Monitoring the response } \\
\text { of cells to apoptosis } \\
\text { inducer drugs }\end{array}$ & $>250 \mathrm{kV} / \mathrm{m}$ & $210 \mathrm{~min}$ & 30 \\
\hline Jurkat T-cells & \multirow{2}{*}{$\begin{array}{l}\text { Making 3D aggregation } \\
\text { of cells for tissue } \\
\text { engineering studies }\end{array}$} & \multirow{2}{*}{$>150 \mathrm{kV} / \mathrm{m}$} & \multirow{2}{*}{$30 \mathrm{~min}$} & \multirow{2}{*}{34} \\
\hline SAOS-2 Osteoblasts & & & & \\
\hline $\begin{array}{l}\text { A549-luc-C8 Human } \\
\text { lung cancer }\end{array}$ & $\begin{array}{l}\text { Separation and collection } \\
\text { of viable lung cancer } \\
\text { cells, followed by } \\
\text { extraction of the nuclei } \\
\text { of cells }\end{array}$ & $>150 \mathrm{kV} / \mathrm{m}$ & $\sim 15 \mathrm{~min}$ & 53 \\
\hline CD34 + Stem cell & $\begin{array}{l}\text { Isolating CD } 34+\text { cells } \\
\text { from bone marrow and } \\
\text { peripheral blood samples }\end{array}$ & $>75 \mathrm{kV} / \mathrm{m}$ & $10 \mathrm{~min}$ & 54 \\
\hline $\begin{array}{l}\text { MDA231 Human } \\
\text { metastatic breast cancer }\end{array}$ & $\begin{array}{l}\text { Separation of breast } \\
\text { cancer cells from blood }\end{array}$ & $>60 \mathrm{kV} / \mathrm{m}$ & $10 \mathrm{~min}$ & 55 \\
\hline Our approach & $\begin{array}{l}\text { Robust immobilisation } \\
\text { of cells to analyse their } \\
\text { shear-induced calcium } \\
\text { signalling }\end{array}$ & $126 \mathrm{kV} / \mathrm{m}$ & $2 \mathrm{~min}$ & Current \\
\hline
\end{tabular}

Table 1. Comparing the magnitude of electric field and duration of exposure to electric field in our study to the ones in the literature.

\section{Methods}

Fabrication of the microelectrodes. For the microelectrodes, gold on chrome films were deposited using physical vapour deposition onto a glass substrate at thickness of $1500 \AA$ and $500 \AA$, respectively. The microelectrodes were then patterned using standard microfabrication techniques including photolithography and etching.

Fabrication of the microchannel. The microchannel was fabricated utilising soft lithography and replica molding techniques ${ }^{57}$. The polydimethysiloxane (PDMS) was prepared using Sylgard 184, with the base to curing agent ratio 10:1 (Dow Corning Corporation, MI). A PDMS microchannel of $500 \times 80 \mu \mathrm{m}$ $(\mathrm{W} \times \mathrm{H})$ was used to apply appropriate suspensions, including the cells in the vicinity of the microelectrodes.

Cell preparation. HEK-293 T-REx (Life Sciences) cell lines stably expressing human TRPV4 were generated as reported elsewhere ${ }^{58}$. Cells were grown in tetracycline-free DMEM media supplemented $10 \%$ FBS, blasticidin $(5 \mu \mathrm{g} / \mathrm{ml})$ and hygromycin $(50 \mu \mathrm{g} / \mathrm{ml})$. TRP channel expression was induced using $0.1 \mu \mathrm{g} / \mathrm{ml}$ of tetracycline $12 \mathrm{~h}$ before each experiment. As negative control we used HEK-293 T-REx cells that were not transfected.

Changes in intracellular $\left[\mathrm{Ca}^{2+}\right]_{\mathrm{i}}$ were measured on cell suspensions obtained by trypsinization of confluent monolayers of wild-type and TRPV4 stably transfected HEK-293 cells. The suspended cells were loaded with Fluo-4AM, washed twice with HEPES-buffered saline solution $(140 \mathrm{mM} \mathrm{NaCl}, 5 \mathrm{mM} \mathrm{KCl}$, $10 \mathrm{mM}$ HEPES, $11 \mathrm{mM}$ D-glucose, $1 \mathrm{mM} \mathrm{MgCl}, 2 \mathrm{mM} \mathrm{CaCl}_{2}$, and $2 \mathrm{mM}$ probenecid, adjusted to $\mathrm{pH}$ $7.4)$, and assayed for intracellular calcium concentration $\left(\left[\mathrm{Ca}^{2+}\right]_{\mathrm{i}}\right)$. Intensity measurements were obtained using an inverted microscope (Nikon Eclipse, TE 2000) equipped with a photomultiplier tube, a near infrared camera (QuantEM:512SC, Photometrics), and a 10× objective (CFI Plan Apo Lambda 10×). The intensity measurements were then processed using NIS Elements, microscope imaging software (Basic Research, Nikon Instruments), thus, enabling the intensity profiles to be obtained.

At the completion of every experiment, the viability of the cells was examined on-chip with propidium iodide (PI) $(10 \mu \mathrm{g} / \mathrm{ml})$ staining.

\section{References}

1. Nahavandi, S. et al. Microfluidic Platforms for the Investigation of Intercellular Signalling Mechanisms. Small 10, 4810-4826 (2014).

2. Kaji, H., Kanada, M., Oyamatsu, D., Matsue, T. \& Nishizawa, M. Microelectrochemical approach to induce local cell adhesion and growth on substrates. Langmuir 20, 16-19 (2004).

3. Simmons, C. S. et al. Integrated strain array for cellular mechanobiology studies. J. Micromech. Microeng. 21, 54016-54025 (2011).

4. Yamamoto, K. \& Ando, J. Endothelial cell and model membranes respond to shear stress by rapidly decreasing the order of their lipid phases. J. Cell Sci. 126, 1227-1234 (2013).

5. Vladkova, T. G. Surface Engineered Polymeric Biomaterials with Improved Biocontact Properties. Int. J. Polym. Sci. 2010, doi: $10.1155 / 2010 / 296094$ (2010)

6. Kato, M. \& Mrksich, M. Rewiring cell adhesion. J. Am. Chem. Soc. 126, 6504-6505 (2004). 
7. Voldman, J. Engineered systems for the physical manipulation of single cells. Curr. Opin. Biotechnol. 17, 532-537 (2006).

8. El-Ali, J., Sorger, P. K. \& Jensen, K. F. Cells on chips. Nature 442, 403-411 (2006).

9. Guo, F. et al. Probing cell-cell communication with microfluidic devices. Lab Chip 13, 3152-3162 (2013).

10. Menachery, A. et al. Counterflow dielectrophoresis for trypanosome enrichment and detection in blood. Sci. Rep. 2, doi: 10.1038/ srep00775 (2012)

11. Hou, H. W. et al. Isolation and retrieval of circulating tumor cells using centrifugal forces. Sci. Rep. 3, doi: 10.1038/srep01259 (2013).

12. Gossett, D. R. et al. Label-free cell separation and sorting in microfluidic systems. Anal. Bioanal. Chem. 397, 3249-3267 (2010).

13. Wang, X. et al. Enhanced cell sorting and manipulation with combined optical tweezer and microfluidic chip technologies. Lab Chip 11, 3656-3662 (2011).

14. Ding, X. et al. On-chip manipulation of single microparticles, cells, and organisms using surface acoustic waves. Proc. Natl. Acad. Sci. USA 109, 11105-11109 (2012).

15. Kilinc, D. \& Lee, G. U. Advances in magnetic tweezers for single molecule and cell biophysics. Integr. Biol. 6, 27-34 (2014).

16. Khoshmanesh, K., Nahavandi, S., Baratchi, S., Mitchell, A. \& Kalantar-zadeh, K. Dielectrophoretic platforms for bio-microfluidic systems. Biosens. Bioelectron. 26, 1800-1814 (2011).

17. Voldman, J. Electrical forces for microscale cell manipulation. Annu. Rev. Biomed. Eng. 8, 425-454 (2006).

18. Di Carlo, D., Aghdam, N. \& Lee, L. P. Single-cell enzyme concentrations, kinetics, and inhibition analysis using high-density hydrodynamic cell isolation arrays. Anal. Chem. 78, 4925-4930 (2006).

19. Khoshmanesh, K. et al. A hydrodynamic microchip for formation of continuous cell chains. Appl. Phys. Lett. 104, doi: $10.1063 / 1.4879457$ (2014).

20. Wlodkowic, D., Faley, S., Zagnoni, M., Wikswo, J. P. \& Cooper, J. M. Microfluidic Single-Cell Array Cytometry for the Analysis of Tumor Apoptosis. Anal. Chem. 81, 5517-5523 (2009).

21. Aubin, H. et al. Directed 3D cell alignment and elongation in microengineered hydrogels. Biomaterials 31, 6941-6951 (2010).

22. Tan, W. \& Desai, T. A. Layer-by-layer microfluidics for biomimetic three-dimensional structures. Biomaterials 25, 1355-1364 (2004).

23. Grier, D. G. A revolution in optical manipulation. Nature 424, 810-816 (2003).

24. Peterman, E. J., Gittes, F. \& Schmidt, C. F. Laser-induced heating in optical traps. Biophys. J. 84, 1308-1316 (2003).

25. Chen, Y. et al. Continuous enrichment of low-abundance cell samples using standing surface acoustic waves (SSAW). Lab Chip 14, 924-930 (2014).

26. Pethig, R. Review Article-Dielectrophoresis: Status of the theory, technology, and applications. Biomicrofluidics 4, 022811 (2010).

27. Soffe, R. et al. Controlled rotation and vibration of patterned cell clusters using dielectrophoresis. Anal. Chem. 87, 2389-2395 (2015).

28. Tang, S.-Y. et al. Using dielectrophoresis to study the dynamic response of single budding yeast cells to Lyticase. Anal. Bioanal. Chem. 407, 3437-3448 (2015).

29. Morgan, H. \& Green, N. G. AC electrokinetics: colloids and nanoparticles. (2003).

30. Khoshmanesh, K. et al. Dynamic Analysis of Drug-Induced Cytotoxicity Using Chip-Based Dielectrophoretic Cell Immobilization Technology. Anal. Chem. 83, 2133-2144 (2011).

31. Hawkins, B. G., Huang, C., Arasanipalai, S. \& Kirby, B. J. Automated Dielectrophoretic Characterization of Mycobacterium smegmatis. Anal. Chem. 83, 3507-3515 (2011).

32. Zhang, P. et al. Raman-Activated Cell Sorting Based on Dielectrophoretic Single-Cell Trap and Release. Anal. Chem. 87, 22822289 (2015).

33. Yang, L. Dielectrophoresis assisted immuno-capture and detection of foodborne pathogenic bacteria in biochips. Talanta 80, 551-558, (2009).

34. Sebastian, A., Buckle, A.-M. \& Markx, G. H. Tissue engineering with electric fields: Immobilization of mammalian cells in multilayer aggregates using dielectrophoresis. Biotechnol. Bioeng. 98, 694-700 (2007).

35. Köhler, R. \& Hoyer, J. in TRP Ion Channel Function in Sensory Transduction and Cellular Signaling Cascades Frontiers in Neuroscience 377-388 (CRC Press, 2006).

36. Mendoza, S. A. et al. TRPV4-mediated endothelial Ca2+ influx and vasodilation in response to shear stress. Am. J. Physiol. Heart Circ. Physiol. 298, H466-H476 (2010).

37. Nilius, B., Vriens, J., Prenen, J., Droogmans, G. \& Voets, T. TRPV4 calcium entry channel: a paradigm for gating diversity. Am. J. Physiol. Cell Physiol. 286, C195-C205 (2004).

38. Baratchi, S. et al. Examination of the role of transient receptor potential vanilloid type 4 in endothelial responses to shear forces. Biomicrofluidics 8, doi: 10.1063/1.4893272 (2014).

39. Xu, H. S. et al. Regulation of a transient receptor potential (TRP) channel by tyrosine phosphorylation - Src family kinasedependent tyrosine phosphorylation of TRPV4 on Tyr-253 mediates its response to hypotonic stress. J. Biol. Chem. 278, 1152011527 (2003).

40. Ku, D. N., Giddens, D. P., Zarins, C. K. \& Glagov, S. Pulsatile flow and atherosclerosis in the human carotid bifurcation. Positive correlation between plaque location and low oscillating shear stress. Arteriosclerosis 5, 293-302 (1985).

41. Potthoff, E. et al. Rapid and Serial Quantification of Adhesion Forces of Yeast and Mammalian Cells. PLoS ONE 7, e52712 (2012).

42. Vancha, A. R. et al. Use of polyethyleneimine polymer in cell culture as attachment factor and lipofection enhancer. $B M C$ Biotechnol. 4, 23-23 (2004).

43. Patel, M., Wilcox, D. A., Giddings, A. M., McKay, T. R. \& Olsen, J. C. 81. Modification of HEK 293 cell integrin expression profile allows convenient large-scale roller bottle production of lentiviral vectors. Mol. Ther. 9, S33-S33 (2004).

44. Lodish, H. B. A., Zipursky, S. L, Matsudaira, P, Baltimore, D, Darnell, J. Molecular Cell Biology 4th edition edn, (W. H. Freeman 2000).

45. Albelda, S. M. \& Buck, C. A. Integrins and other cell adhesion molecules. FASEB J. 4, 2868-2880 (1990).

46. Zhang, K. \& Chen, J. The regulation of integrin function by divalent cations. Cell Adh. Migr. 6, 20-29 (2012).

47. Leitinger, B., McDowall, A., Stanley, P. \& Hogg, N. The regulation of integrin function by Ca2+. Biochim. Biophys. Acta 1498, 91-98 (2000).

48. Nasabi, M., Khoshmanesh, K., Tovar-Lopez, F. J., Kalantar-zadeh, K. \& Mitchell, A. Dielectrophoresis with 3D microelectrodes fabricated by surface tension assisted lithography. Electrophoresis 34, 3150-3154 (2013).

49. Ojeda-May, P. \& Garcia, M. E. Electric Field-Driven Disruption of a Native $\beta$-Sheet Protein Conformation and Generation of a Helix-Structure. Biophys. J. 99, 595-599 (2010).

50. Mercier-Bonin, M., Ouazzani, K., Schmitz, P. \& Lorthois, S. Study of bioadhesion on a flat plate with a yeast/glass model system. J. Colloid Interface Sci. 271, 342-350 (2004).

51. Shipman, C. Evaluation of 4-(2-Hydroxyethyl)-1-piperazineëthanesulfonic Acid (HEPES) as a Tissue Culture Buffer. Exp. Biol. Med. 130, 305-310 (1969). 
52. Delmas, P., Hao, J. \& Rodat-Despoix, L. Molecular mechanisms of mechanotransduction in mammalian sensory neurons. Nature Rev. Neurosci. 12, 139-153 (2011).

53. Tai, C. H., Hsiung, S. K., Chen, C. Y., Tsai, M. L. \& Lee, G. B. Automatic microfluidic platform for cell separation and nucleus collection. Biomed. Microdevices 9, 533-543 (2007).

54. Talary, M. S., Mills, K. I., Hoy, T., Burnett, A. K. \& Pethig, R. Dielectrophoretic separation and enrichment of CD34+ cell subpopulation from bone marrow and peripheral blood stem cells. Med. Biol. Eng. Comput. 33, 235-237 (1995).

55. Becker, F. F. et al. Separation of human breast cancer cells from blood by differential dielectric affinity. Proc. Natl. Acad. Sci. USA 92, 860-864 (1995).

56. Gu, Y. \& Gu, C. Physiological and Pathological Functions of Mechanosensitive Ion Channels. Mol. Neurobiol. 50, 339-347 (2014).

57. Whitesides, G. M., Ostuni, E., Takayama, S., Jiang, X. Y. \& Ingber, D. E. Soft lithography in biology and biochemistry. Annu. Rev. Biomed. Eng. 3, 335-373 (2001).

58. Poole, D. P. et al. Protease-activated Receptor 2 (PAR(2)) Protein and Transient Receptor Potential Vanilloid 4 (TRPV4) Protein Coupling Is Required for Sustained Inflammatory Signaling. J. Biol. Chem. 288, 5790-5802 (2013).

\section{Acknowledgements}

K. Khoshmanesh acknowledges the Australian Research Council for funding under Discovery Early Career Researcher Award (DECRA) scheme, (project DE120101402).

\section{Author Contributions}

R.S. and S.B. performed all experiments, and evaluated the data. R.S. and M.N. fabricated the microfluidic chips. R.S., S.B. and K.K. designed experiments. S.-Y.T. and K.K. performed analytical and numerical calculations. R.S., S.B., K.K. P.M. and A.M. wrote and edited the manuscript. K.K., P.M. and A.M. coordinated and supervised the work.

\section{Additional Information}

Supplementary information accompanies this paper at http://www.nature.com/srep

Competing financial interests: The authors declare no competing financial interests.

How to cite this article: Soffe, R. et al. Analysing calcium signalling of cells under high shear flows using discontinuous dielectrophoresis. Sci. Rep. 5, 11973; doi: 10.1038/srep11973 (2015).

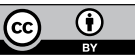

This work is licensed under a Creative Commons Attribution 4.0 International License. The images or other third party material in this article are included in the article's Creative Commons license, unless indicated otherwise in the credit line; if the material is not included under the Creative Commons license, users will need to obtain permission from the license holder to reproduce the material. To view a copy of this license, visit http://creativecommons.org/licenses/by/4.0/ 